\section{Mehr als Zahnputzecke und Zahndisko}

Seit mehr als 20 Jahren tourt das Krocky-Mobil, ein Angebot der Initiative Kiefergesundheit e.V. (IKG), durch die Republik alljährlich kommt es in rund 40 Städte und informiert auf diese Weise etwa 10.000 Kinder zur kiefer- und zahnmedizinischen Gesundheit.

Fast jedes fünfte dreijährige Kind in Deutschland leidet bereits unter Karies, häufig ist schon das Milchzahngebiss teilweise zerstört. Daraus resultieren gravierende Folgen für die Gesundheit der bleibenden Dentition wie erhöhtes Kariesrisiko, Zahnentwicklungsstörung, Zahndurchbruchprobleme. Vor diesem Hintergrund hat für das Team des Krocky-Mobils der Zahn- und Stützzonenerhalt im Milchgebiss Priorität.

Anfang Juli 2017 hat der Info-Bus mit dem Team der kieferorthopädischen Praxis Dr. Heike Fleddermann in Neuss den Kindergarten Blaues Haus und den evangelischen Kindergarten Abteiweg besucht. „Wir erklären nicht nur das richtige Zähneputzen“, sagt Dr. Fleddermann, „wir klären auch über Aufgaben und Funktion der Zähne, über Ernährung, süße Getränke und Fluoridierung auf. Besonders wichtig ist es, auch über die Vermeidung gebissschädigender Angewohnheiten wie Schnuller lutschen, Daumen nuckeln oder Lippen beißen aufzuklären.“

Zahnfehlstellungen und Kieferanomalien sowie deren Spätfolgen können die Betroffenen ein Leben lang belasten. Darum sei die Früherkennung orofazialer Dysfunktionen wie etwa Mundatmung, Zungendysfunktion und infantiles Schluckmuster immens wichtig, um Zahnstellungsanomalien oder Wachstumshemmung vorbeugen zu können. „Weit über die Hälfte der Zahn- oder Gebissfehlstellungen sind nicht angeboren, sondern erworben und hätten somit vermieden werden können“, erklärt Dr. Fleddermann.

Im Krocky-Mobil befinden sich unter anderem eine Zahnputzecke und eine „Zahndisko“, im Mittelpunkt jedes Besuchs aber steht Krocky, das Schnuller lutschende Krokodil mit den vielen Zähnen.

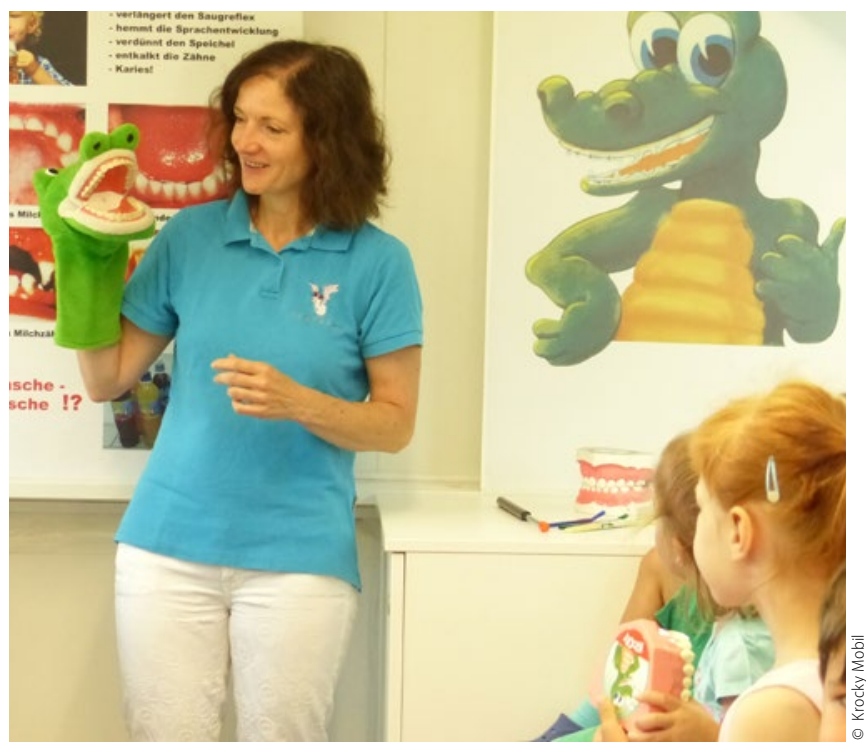

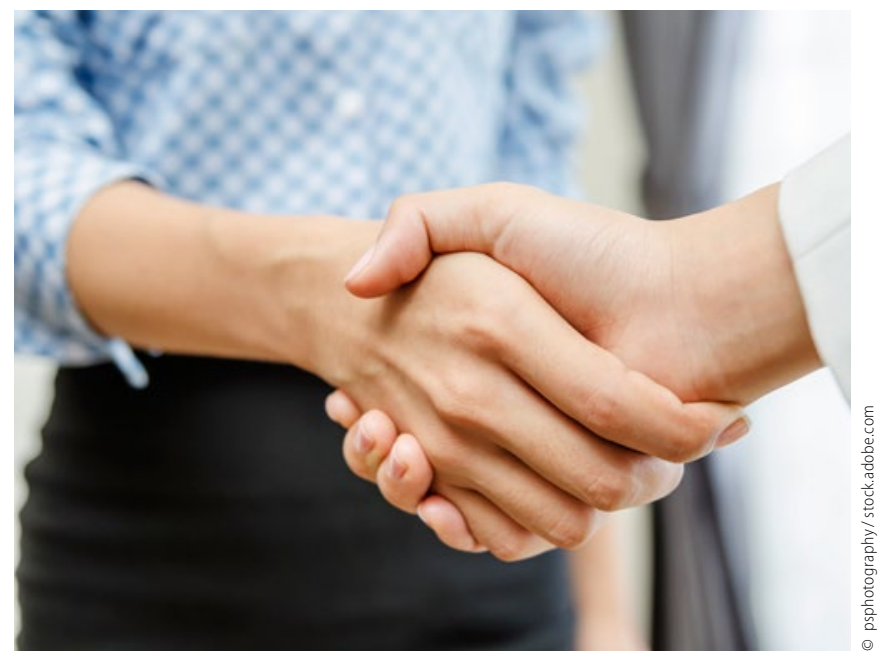

ApoBank-Studie Zukunftsbild Heilberufler 2030 Dienstleister des Vertrauens

Die Rolle des Heilberuflers und die Patientenversorgung wird sich in den nächsten Jahren ändern. Grund dafür dürften die zunehmende Feminisierung der Heilberufe sein, der Trend zur Teilzeitbeschäftigung und Kooperationen, verbunden mit dem demografischen Wandel und dem technologischen Fortschritt. Diese Einschätzung ergab eine Befragung von rund 400 Ärzten, Zahnärzten und Apothekern, durchgeführt von der Deutschen Apotheker- und Ärztebank und dem Meinungsforschungsinstitut forsa zum „Zukunftsbild Heilberufler 2030“.

Demnach wird laut 83 Prozent der Befragten der Heilberufler im Jahr 2030 als Dienstleister wahrgenommen. Trotzdem glauben 71 Prozent, dass sie auch im Jahr 2030 hohes Vertrauen in der Bevölkerung genießen werden.

Außerdem wird der Patient anspruchsvoller, sind sich 91 Prozent sicher, und (85 Prozent) informierter, zudem dürften die künftigen Patienten laut 59 Prozent häufiger bereit sein, für Gesundheitsleistungen selbst zu zahlen und Präventionsmaßnahmen zu betreiben.

Die stationäre und die ambulante Versorgung im ländlichen Bereich übernehmen nach Ansicht von zwei Drittel der Heilberufler künftig Krankenhäuser.

\section{Digitalisierung ersetzt künftig Heilberufler teilweise}

86 Prozent aller Heilberufler gehen davon aus, dass die Digitalisierung ihre Arbeit in Zukunft sinnvoll unterstützen wird, 40 Prozent der Befragten glauben sogar, dass die Digitalisierung künftig den Heilberufler in Teilen ersetzen wird.

Während Ärztinnen im Jahr 2030 sich als Angestellte im ambulanten Sektor vorrangig in Teilzeitarbeit (66 Prozent) und männliche (Fach-) Ärzte sich sowohl in der Selbstständigkeit (20 Prozent) als auch in der Anstellung in einem Krankenhaus (19 Prozent) sehen, zeigt die Befragung der Zahnärzte, dass sowohl Zahnärzte (35 Prozent) als auch Zahnärztinnen (23 Prozent) weiterhin vorrangig selbstständig in einer Berufsausübungsgemeinschaft arbeiten wollen. Mehr als 60 Prozent der weiblichen Zahnärzte gehen davon aus, dass sie 2030 in Teilzeit arbeiten werden, drei Viertel der Männer wollen in Vollzeit als Zahnarzt tätig sein. 